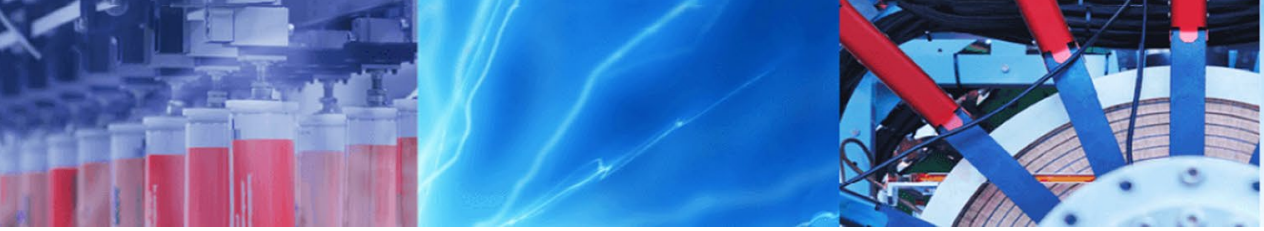

Research Article

\title{
Influence of heat treatment on corrosion rate of aluminium A356 reinforced with mica and titanium di oxide
}

\author{
S. Prajval ${ }^{1,2}$ (D) P. Rajendra Prasad ${ }^{3}$
}

Received: 10 May 2019 / Accepted: 13 November 2019 / Published online: 21 November 2019

(c) Springer Nature Switzerland AG 2019

\begin{abstract}
Composite material plays important role in the field of engineering and has vast applications in the aerospace, marine industries, automobiles, recreational etc. Researchers are always engaged in identifying the hidden parameters of the composites. In this present study, aluminium A356 alloy is proportionally mixed with the reinforcements like titanium di oxide $\left(\mathrm{TiO}_{2}\right)$ and mica by using vortex method. The matrix $\mathrm{A} 356$ is mixed with equal proportions of $\mathrm{TiO}_{2}$ and mica ( $1 \mathrm{wt} \%$, $2 \mathrm{wt} \%, 3 \mathrm{wt} \%, 4 \mathrm{wt} \%$ and $5 \mathrm{wt} \%)$ and different castings formed are subjected to various heat treatment process. Once the different ageing conditions are achieved, the specimens are studied for the corrosion behavior. Results suggest that the specimen with double ageing $(4 \mathrm{~h})$ is having greater resistance to corrosion. The density of the prepared casting decreased with increase in reinforcement.
\end{abstract}

Keywords Composites $\cdot \mathrm{A} 356 \cdot \mathrm{Mica} \cdot \mathrm{TiO}_{2} \cdot$ Ageing conditions and corrosion resistance

\section{Introduction}

Researchers are always identifying materials with many advantages like density, corrosion resistance, long life, very economical, good strength etc. A monolithic material does not always provide such needy performance. Hence a need for hybrid materials is explored around the world through research and development. A composite material fills this demand with its high strength to weight ratio, low density, machinability and other various properties.

In this present study, aluminium A356 is the matrix material and reinforced with mica and $\mathrm{TiO}_{2}$ with equal weight percentage. A356 belong to a group of hypo eutectic Al-Si alloy and has a wide field of application in automotive and avionics industries [1]. Alloy A356.0 has great elongation higher strength and considerably higher ductility than 356.0. Impurities less and hence have wide application in airframe casting, machine parts, truck chasses [2]. Titanium dioxide, also known as titanium is the naturally occurring oxide of titanium. It has a wide range of applications, from paint to sunscreen to food coloring. Mica is a complex aluminosilicate mineral. Mica is plate or sheet like structure. Mica has high toughness, good physical, thermal, mechanical properties. Many investigations on composites are done by researchers.

Mohan Vanarotti et al. studied the synthesis and characterization of aluminium alloy A356 and silicon carbide and reveals reasonable increase in hardness and decrease of ductility with increasing silicon carbide [3].

Maninder singh et al. studied the performance of aluminium based metal matrix composites with $\mathrm{SiO}_{2}$ and $\mathrm{TiO}_{2}$ as reinforced particles and concludes that the addition of reinforcements increases the hardness and wear resistance [4].

Sharath Kumar et al. investigated the wear loss in aluminium, silicon carbide and mica hybrid composites and

$\triangle$ S. Prajval, prajval.shekar@gmail.com | ${ }^{1}$ VTU-RRC, Belagavi, India. ${ }^{2}$ Department of Mechanical Engineering, G. Madegowda Institute of Technology, Mandya District, Karnataka, India. ${ }^{3}$ G.V.Acharya Institute of Engineering and Technology (GVAIET), Shelu, Karjat, Raigad, Maharashtra 410201, India. 
suggests when the mica is added, it reduces the wear loss and increases the wear resistance of the material [5].

\section{Aim of the present study}

In this present investigation, aluminium A356 alloy based hybrid composite is been prepared by using $\mathrm{TiO}_{2}$ and mica particles as reinforcement for equal proportions ( $1 \mathrm{wt} \%, 2 \mathrm{wt} \%, 3 \mathrm{wt} \%, 4 \mathrm{wt} \%$ and $5 \mathrm{wt} \%$ ) by stir casting method and investigated for the corrosion resistance which are highly important criteria for the hybrid material to survive in marine applications [6].

\section{Processing of MMC's}

In this process, the specimens were prepared using stir casting technique. Aluminium A356 alloy was taken as the matrix material. Titanium and Mica were chosen as the reinforcement to form the hybrid composite material. Initially A356 alloy was heated to $700{ }^{\circ} \mathrm{C}$ so as to obtain the molten material in an electric furnace. The prepared mica and $\mathrm{TiO}_{2}$ particles having mesh size in the range 100-250 $\mu$ was preheated to a temperature of $450{ }^{\circ} \mathrm{C}$ for at least $1 \mathrm{~h}$ to remove the moisture content and absorbed gases in the particles. Degassing of molten metal was evacuated by adding hexachloro- ethane tablets. Liquid metal temperature was maintained at $700^{\circ} \mathrm{C}$ with sufficient viscosity. The liquid metal was stirred at a speed of 500 rpm for 10-15 min with the help of impeller to create sufficient vortex [7]. The stir speed chosen is high enough to get a sufficient vortex for proper mixing of the reinforcement particles with the liquid metal. At the same time, stir speed is low enough to avoid the gas and air entrapment in the molten metal. The $1 \%$ weight preheated particles were incorporated laterally into the vortex of the molten metal. $1 \%$ magnesium was added to the molten metal to increase the wettability of the particles with the molten material. Stirring speed was maintained at $500 \mathrm{rpm}$ for next $15 \mathrm{~min}$ to ensure the proper mixing [8]. After this stage, the molten mixture was drained into the mould. To accomplish the uniform solidification of the molten metal, the mould was preheated to $250^{\circ} \mathrm{C}$ for $30 \mathrm{~min}$ [9]. Thus, particles are incorporated successfully to form hybrid composite material by using the stir casting technique [10]. Later $2 \mathrm{wt} \%$, $3 \mathrm{wt} \%, 4 \mathrm{wt} \%$ and $5 \mathrm{wt} \%$ by equal weight proportions of mica and $\mathrm{TiO}_{2}$ were replaced to prepare the test specimen and tested for different aging condition.

\section{Heat treatment process}

The heat treatment steps for the MMCs are as follows,

1. Solutionizing Solutionizing at $540^{\circ} \mathrm{C}$ for $6 \mathrm{~h}$ followed by quenching into water at room temperature was executed on the prepared specimens.

2. Single Ageing once quenching is done, the specimens are heated to a temperature of $140^{\circ} \mathrm{C}$ for about $12 \mathrm{~h}$ is carried out.

3. Double Ageing 1 In this process, the specimens are heated to a temperature of $190^{\circ} \mathrm{C}$ for about $2 \mathrm{~h}$ is carried out.

4. Double Ageing 2 In this process, the specimens are heated to a temperature of $190^{\circ} \mathrm{C}$ for about $4 \mathrm{~h}$ is carried out [11].

\section{Corrosion test}

Corrosion test was carried out by dipping the specimens in the prepared solutions in separate trays. Solutions, each with 0.1 normal $\mathrm{HCL}, 5 \% \mathrm{NaCl}$ and Sea Water were taken and the specimens were dipped into it for duration of $96 \mathrm{~h}$ (ASTM B117). The specimens were later rinsed with water and weighed in a electronic weighing scale [12].

Figure 1, 2 and 3 shows the corrosion behavior of the as-cast samples and it is observed that the corrosion resistance has increased as there in increase in reinforcement. Small amount of corrosion is evidenced in $\mathrm{HCl}$ but corrosion rate in Sea water and $\mathrm{NaCl}$ in negligible. This may be due to resistance to corrosion by the hard reinforcement material.

The above Figs. 4, 5 and 6 shows that the corrosion resistance has increased as there in increase in reinforcement and at different ageing conditions. Small amount of corrosion is evidenced in $\mathrm{HCl}$ and corrosion rate in Sea water and $\mathrm{NaCl}$ in negligible. Double ageing $(4 \mathrm{~h})$ has exhibited substantial improvement than the base alloy [13]. This may be attributed to increased precipitate in grain boundary distribution during heat treatment and ageing and finer grain size after stretching resulting in increased inter-granular corrosion resistance [14]. The same can be evidenced in the digital photographs of various aged conditions in various solutions. Pitting corrosion is very predominant in as-cast condition and is least in double aged with strain/stretching condition [15, 16]. Figures 7,8 and 9 shows the micrograph images, 
Fig. 1 Corrosion rate verses samples with different reinforcement in 0.1 normal $\mathrm{HCl}$

Fig. 2 Corrosion rate verses samples with different reinforcement in $5 \% \mathrm{NaCl}$

Fig. 3 Corrosion rate verses samples with different reinforcement in sea water
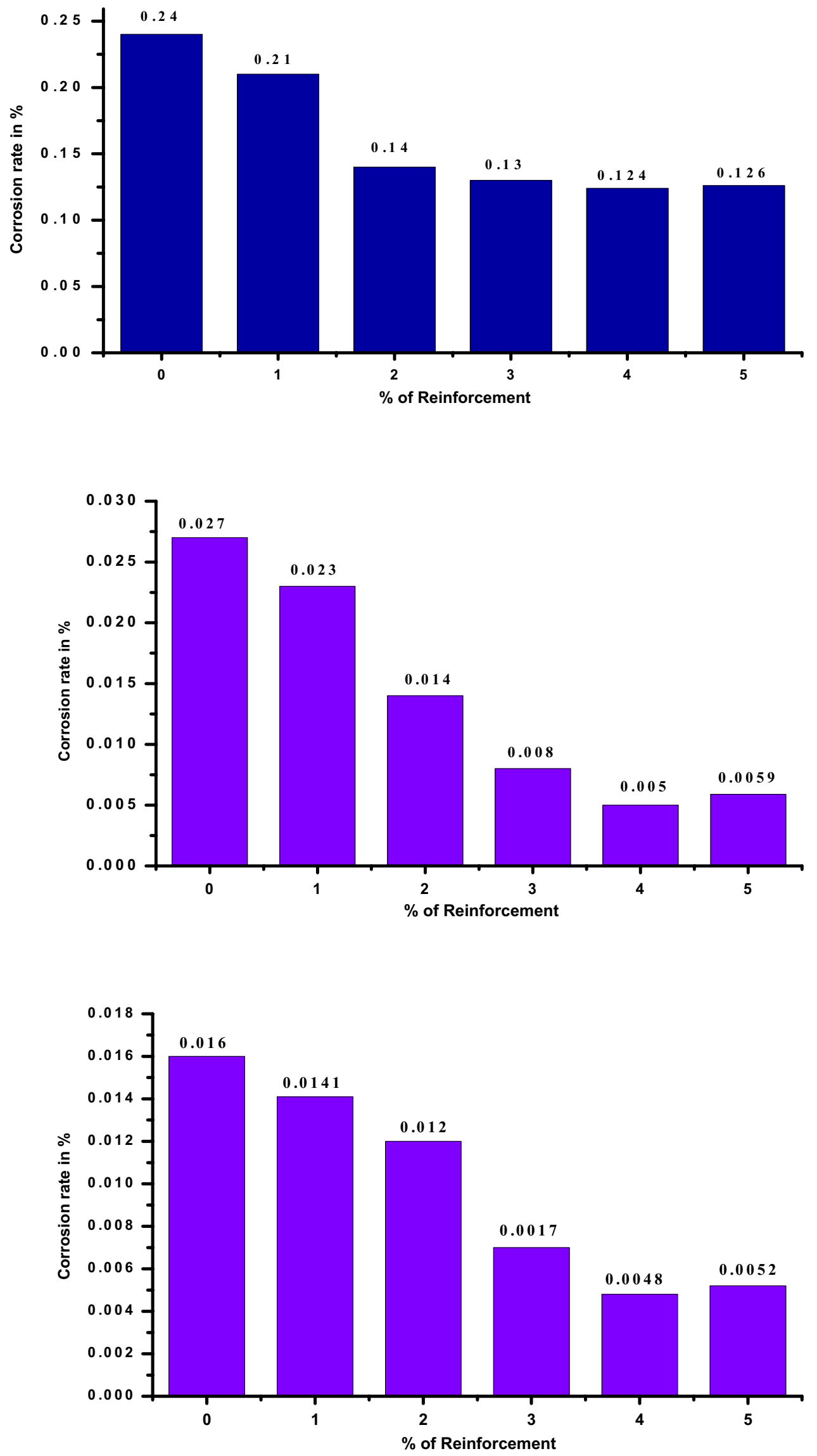

SN Applied Sciences

A SPRINGER NATURE journal 
Fig. 4 Corrosion rate verses different samples at different ageing conditions with 0.1 normal $\mathrm{HCl}$
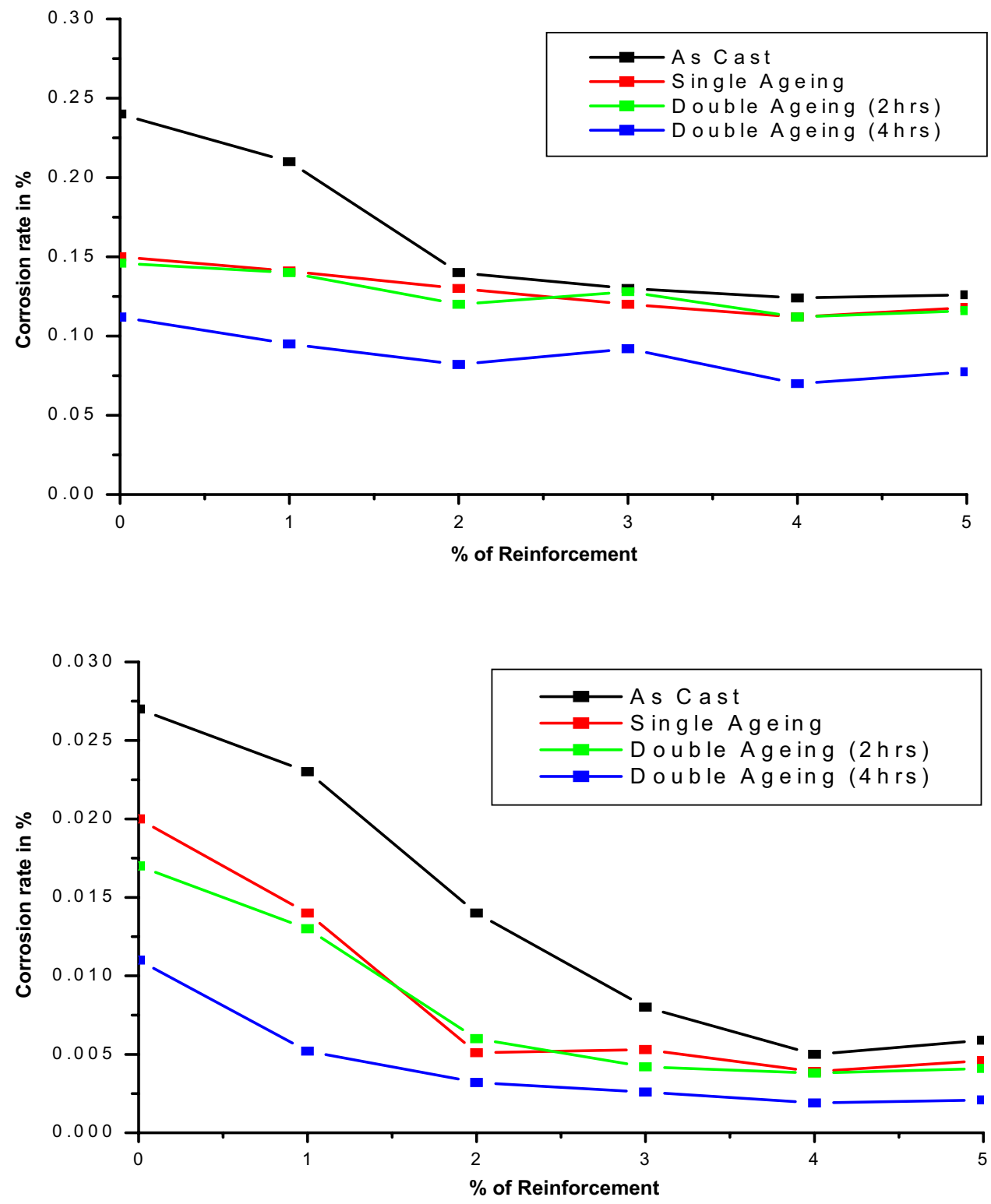

Fig. 5 Corrosion rate verses different samples at different ageing conditions with $5 \%$ $\mathrm{NaCl}$ where the corrosion causes pitting on the surface of the specimens.

\section{Conclusions}

1. Resistance to corrosion has increased as there is an increase in reinforcement and at different ageing conditions. Corrosion is evidenced in $\mathrm{HCl}$ but very mini- mum in Sea water and $\mathrm{NaCl}$. Double ageing $(4 \mathrm{~h})$ has exhibited substantial corrosion resistance compared to as-cast.

2. This improvement in resistance to corrosion may be attributed to increased precipitate in grain boundary distribution during heat treatment/ageing and finer grain size after stretching resulting in increased intergranular corrosion resistance. 
Fig. 6 Corrosion rate verses different samples at different ageing conditions with sea water
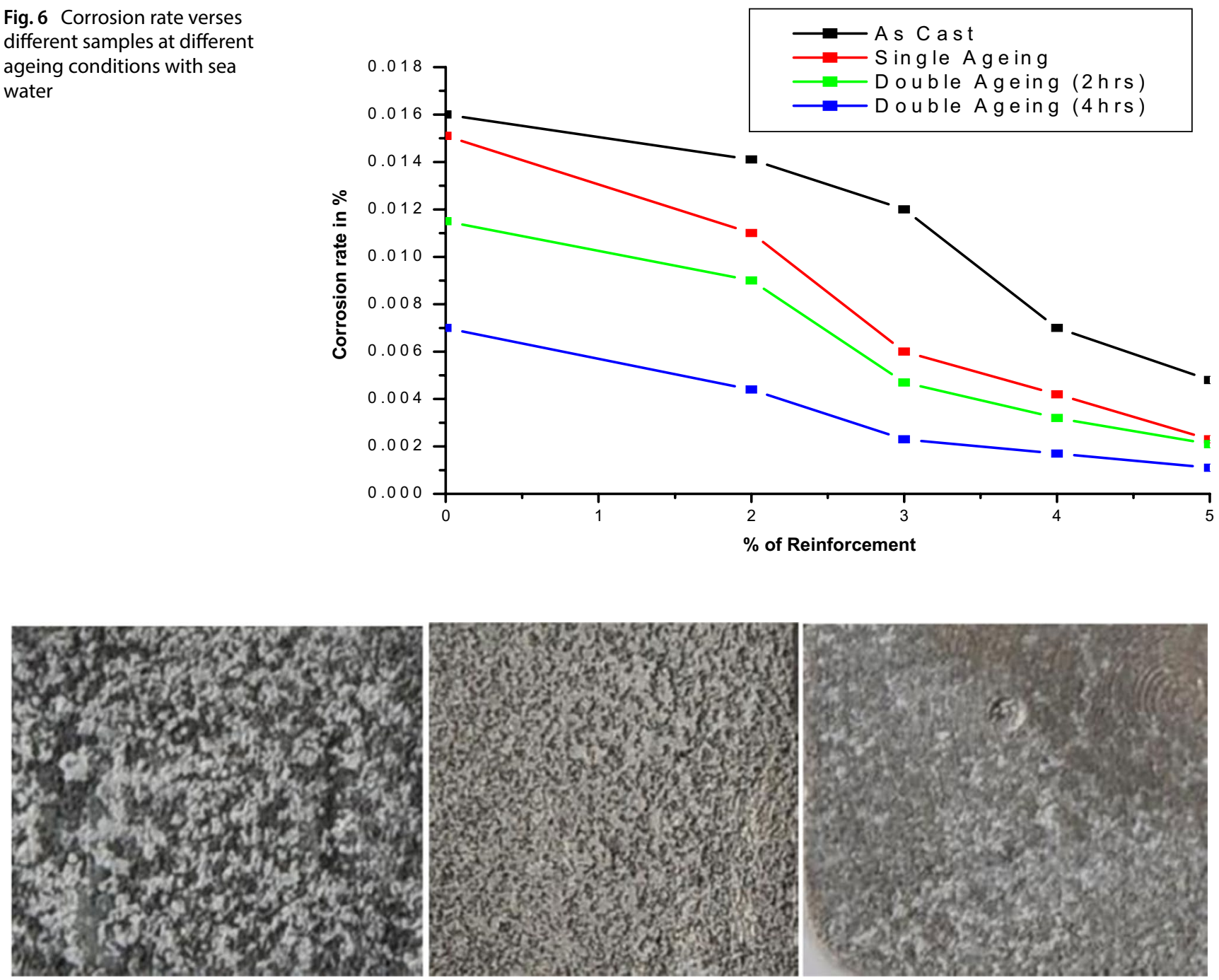

Fig. 7 Pitting corrosion on the flat surface of single aged specimen tested with 0.1 normal $\mathrm{HCl}, 5 \% \mathrm{NaCl}$ and sea water for $96 \mathrm{~h}$
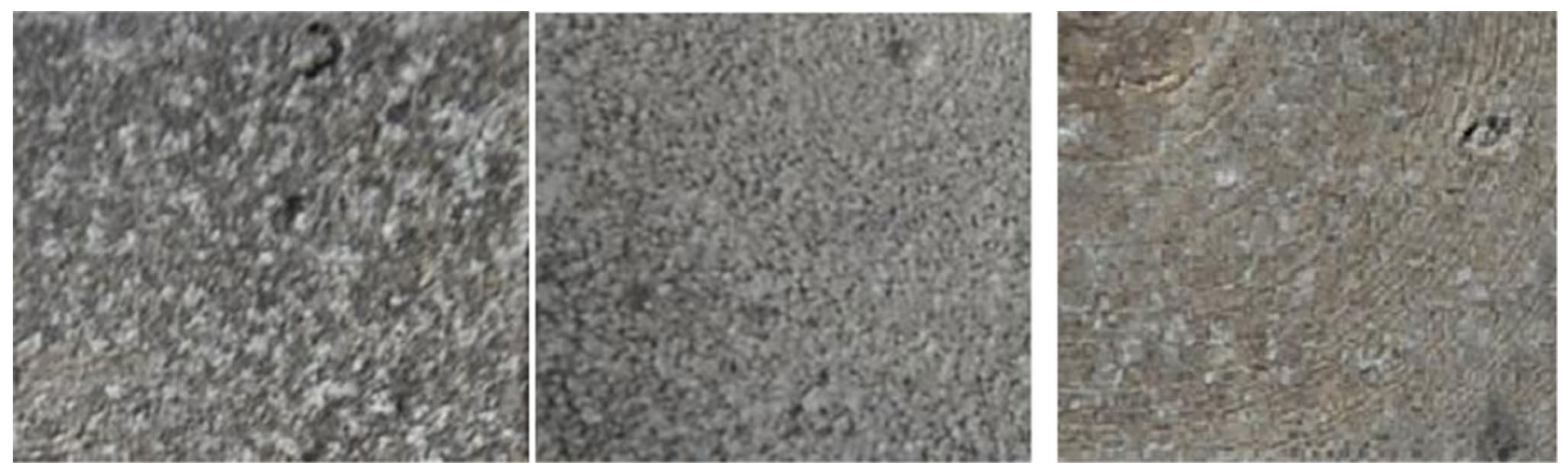

Fig. 8 Pitting corrosion on the flat surface of double aged specimen tested with 0.1 normal $\mathrm{HCl}, 5 \% \mathrm{NaCl}$ and sea water for $96 \mathrm{~h}$ 

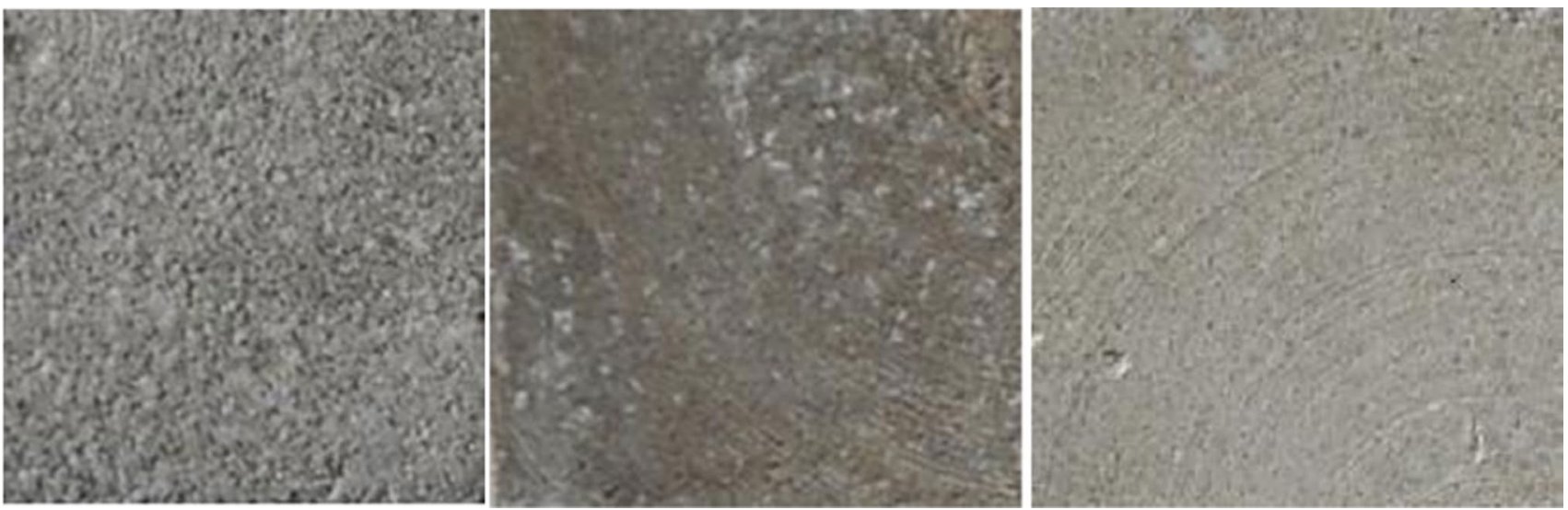

Fig. 9 Pitting corrosion on the flat surface of double aged with strain/stretching specimen tested with 0.1 normal $\mathrm{HCl}, 5 \% \mathrm{NaCl}$ and sea water for $96 \mathrm{~h}$

\section{Compliance with ethical standards}

Conflict of interest The authors declare that they have no conflict of interest.

\section{References}

1. Phrahakar K et al (2012) Experimental studies on mechanical properties of E-glass short fibers and fly ash reinforced Al7075 hybrid metal matrix composites. Int J Mech Ind Eng 1(4):111-115

2. Nagaral $M$ et al (2013) Mechanical behaviour of aluminium 6061 alloy reinforced with $\mathrm{Al}_{2} \mathrm{O}_{3}$ and graphite particulate hybrid metal matrix composites. Int J Res Eng Technol 1(2):193-198

3. Sreenivasa Reddy $M$ et al (2014) Influence of reinforcement and heat treatment on mechanical and wear properties of $\mathrm{Al}$ 7075 based hybrid composite. In: International conference on advances in manufacturing and materials engineering. pp 508-516

4. Shiva Prasad D et al (2011) Production and mechanical properties of A356.2/RHA composites. Int J Adv Sci Technol 33:51-57

5. Shoba $C$ et al (2014) Investigation on mechanical properties of aluminium hybrid composites. J Mater Res Technol (JMR\&T) 3:79-85

6. Vignesh V et al (2014) Fabrication, surface morphology and corrosion investigation of $\mathrm{Al} 7075-\mathrm{Al}_{2} \mathrm{O}_{3}$ matrix composite in sea water and industrial environment. In: 12th Global congress on manufacturing and management. pp 607-613

7. Khanaa OP (2007) Material science and metallurgy. Dhanpat Rai Publications, New Delhi, pp 2-4

8. Abdulwahab M et al (2012) Effect of thermal ageing treatment on the mechanical properties of antimony modified, Al356-type Al-Si-Mg alloy. JMES 4:87-92
9. Wei-Min MAO et al (2012) Rheo-squeeze casting of semisold A356 aluminium alloy slurry. Elsevier, Amsterdam, pp $1769-1773$

10. Srinivasu R (2014) Friction stir surfacing of cast A356 aluminium-silicon alloy with boron carbide and molybdenum disulphide powders. Elsevier, Amsterdam, pp 1-7

11. Alhawari KS et al (2013) Wear properties of $\mathrm{A} 356 / \mathrm{Al}_{2} \mathrm{O}_{3}$ metal matrix composites produced by semisolid processing. Elsevier, Amsterdam, pp 186-192

12. Auradi $V$ et al (2014) Processing of $B_{4} C$ particulate reinforced 6061 aluminium matrix composites by melt stirring involving two-step addition. Elsevier, Amsterdam, pp 1068-1076

13. Sridhar Raja KS et al (2015) Effect of boron carbide particle in wear characteristic cast aluminium A356 composite. IOSR J Mech Civ Eng 20:73-77

14. Mali A et al (2015) Effect of hybrid reinforcement on mechanical behaviour of aluminium matrix composite. Int J Eng Res Technol (IJERT) 4(1):130-133

15. Ramesh D et al (2010) Effect of weigth percentage on mechanical properties of frit particulate reinforced Al6061 composite. ARPN J Eng Appl Sci 5:32-36

16. Prajval $S$ et al (2017) Influence of heat treatment on tribological properties and corrosion resistance of aluminium A356 alloy reinforced with mica and titanium di oxide hybrid composite at different aging conditions. Int J Eng Res 5:16-21

Publisher's Note Springer Nature remains neutral with regard to jurisdictional claims in published maps and institutional affiliations. 